\title{
GRISORIXIN, AN IONOPHOROUS ANTIBIOTIC OF THE NIGERICIN GROUP \\ II. CHEMICAL AND STRUCTURAL STUDY OF GRISORIXIN AND SOME DERIVATIVES
}

Pierre Gachon* and Alain Kergomard

Laboratoire de Chimie Organique Biologique, Université de Clermont-Ferrand

B. P. 45, 63170 Aubière, France

(Received for publication January 21, 1975)

\begin{abstract}
Grisorixin, a polycyclic polyether antibiotic of the nigericin group, showed ionophorous properties. The conformations of crystallized grisorixin and its metallic salts are very similar and are compared in this paper. The physico-chemical properties of the salts are described. The chemical oxidation of grisorixin methyl ester allowed us to isolate several oxidation products whose structures are described.
\end{abstract}

Grisorixin is a polycyclic polyether ionophorous antibiotic, active against gram-positive bacteria and fungi, and produced by a Streptomyces griseus. The production and the structure of this antibiotic are described in the previous paper ${ }^{1)}$. In the present paper, we describe the conformation of grisorixin and its metallic salts, and the chemical and spectral study of derivatives we have prepared.

\section{Structure of Grisorixin and its Monovalent Metal Salts}

The structure of crystalline grisorixin monohydrate has been elucidated by AlLEAUme (unpublished data). The molecule takes a cyclic conformation (Fig. 1) similar to those of its $\mathrm{Ag}^{+}$and $\mathrm{Tl}^{+}$salts ${ }^{2,3)}$ (Fig. 2). In the uncomplexed monohydrate, the water molecule replaces the metal ion, and is hydrogen-bonded to two oxygen atoms and one hydrogen atom of the ligand. The cyclic conformation is further stabilized by an intramolecular hydrogen bond between the carboxyl oxygen and the terminal $\mathrm{OH}$. A study of the effect of dilution on the position of the carbonyl peak of grisorixin in the IR spectrum in $\mathrm{CHCl}_{3}$ showed the same small effect previously observed for nigericin and monensin ${ }^{4)}$, corroborating the intramolecular

Fig. 1. Conformation of grisorixin monohydrate

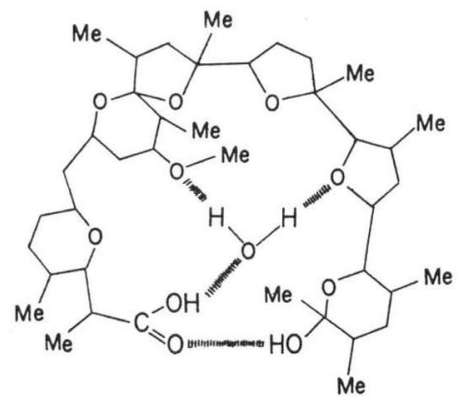

Fig. 2. Conformation of grisorixin salts $\mathrm{M}=\mathrm{Ag}$ or $\mathrm{Tl}$

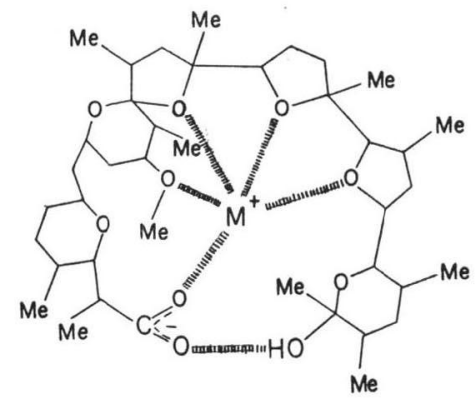

* To whom correspondence should be addressed. Present address: Institute for Enzyme Research, 1710 University Avenue, Madison, Wisconsin 53706, U.S.A. 
Table 1. Association constants of monovalent cation salts of grisorixin determined at $25^{\circ} \mathrm{C}$ in methanol

\begin{tabular}{c|c}
\hline Cation & $\log \mathrm{K}_{\mathrm{A}}$ \\
\cline { 1 - 2 } $\mathrm{Li}^{+}$ & 2.42 \\
$\mathrm{Cs}^{+}$ & 3.19 \\
$\mathrm{Na}^{+}$ & 4.06 \\
$\mathrm{Rb}^{+}$ & 4.10 \\
$\mathrm{~K}^{+}$ & 5.24 \\
$\mathrm{Tl}^{+}$ & 5.85 \\
$\mathrm{Ag}^{+}$ & 6.91 \\
\hline
\end{tabular}

nature of the hydrogen bond $(\nu \mathrm{C}=\mathrm{O}, 1707$ $\mathrm{cm}^{-1}$ at $6.2 \times 10^{-2} \mathrm{M} ; \nu \mathrm{C}=\mathrm{O}, 1699 \mathrm{~cm}^{-1}$ at $\left.6.2 \times 10^{-4} \mathrm{M}\right)$.

We have prepared the $\mathrm{Na}^{+}, \mathrm{K}^{+}, \mathrm{Ag}^{+}$and $\mathrm{Tl}^{+}$crystalline salts of grisorixin. The $\mathrm{K}^{+}$and $\mathrm{Ag}^{+}$salts are isomorphous. The other monovalent cations- $\mathrm{Li}^{+}, \mathrm{Rb}^{+}$, and $\mathrm{Cs}^{+}$-only give amorphous salts obtained as solid forms. The association constants of these salts (Table 1) have been determined by potentiometric and conductometric methods ${ }^{5}$, and the results ob-

tained show that grisorixin binds strongly to each of these monovalent ions, without, however, a particular selectivity for any one of them.

As in the case for most antibiotics of the nigericin group, complexed salts are formed when the cation is surrounded by the helicoidal chain of the molecule, with the cation linked by coordinate bonds to four oxygen atoms of the polycyclic polyether chain (Fig. 2). The bond between the cation and one of the oxygens of the carboxylate group is clearly shorter than the others, which corroborates the salt-like nature of the complex, as opposed to a mere coordination complex.

The NMR study of the $\mathrm{K}^{+}$salt of grisorixin shows the participation of the methoxyl group in cation complexation. This is also true for the $\mathrm{Ag}^{+}$and $\mathrm{Tl}^{+}$salts. The signal of this methoxyl group is shifted $0.16 \mathrm{ppm}$ downfield compared with grisorixin itself, in acetone- $\mathrm{D}_{6}$, and $0.21 \mathrm{ppm}$ downfield compared with grisorixin itself in $\mathrm{CCl}_{4}$. Other signals are also shifted in the methyl and methylene regions (Fig. 3).

The mass spectra of the $\mathrm{Na}^{+}$and $\mathrm{K}^{+}$salts of grisorixin show very different fragmentation processes from those observed in the case of the uncomplexed acid molecule. Most peaks in

Fig. 3. NMR spectrum of grisorixin potassium salt (acetone- $\mathrm{D}_{6}, 100 \mathrm{MHz}$ )

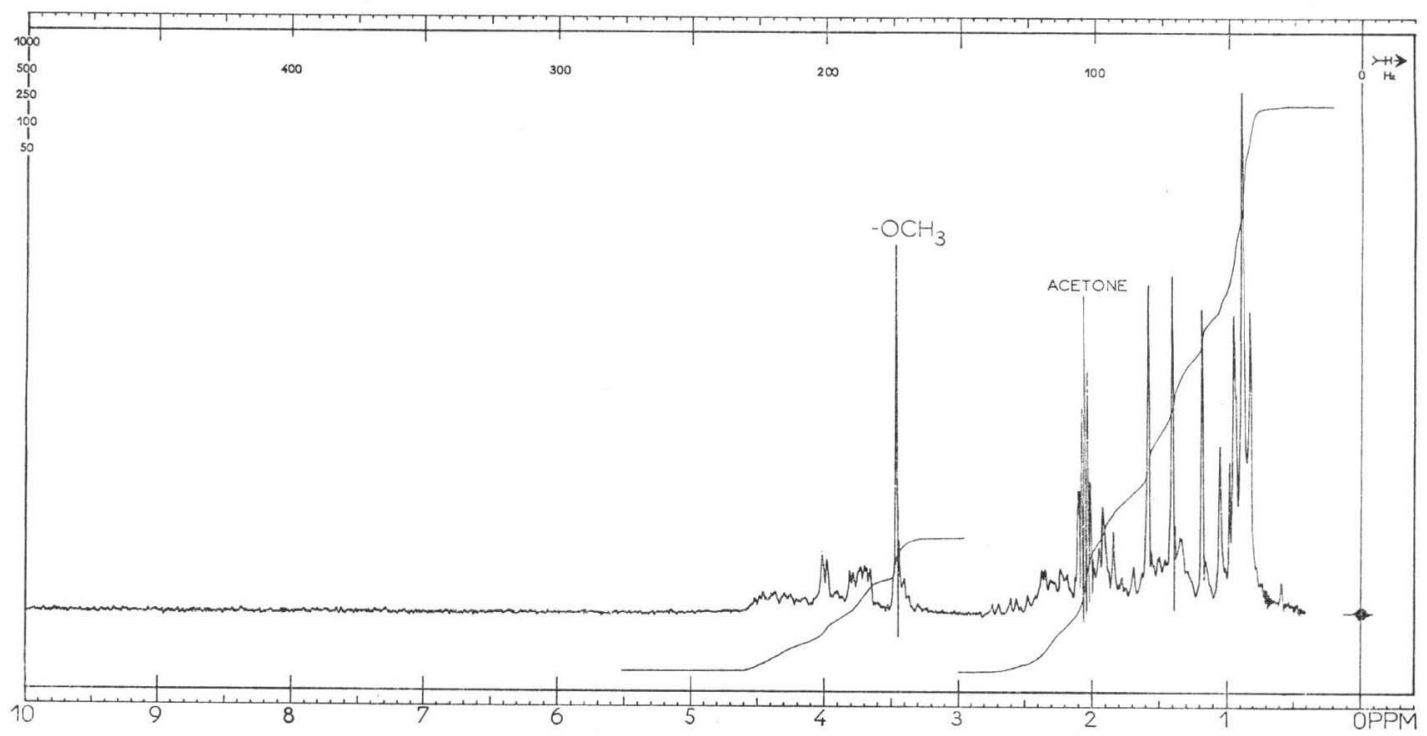


Fig. 4. Mass spectrum of grisorixin potassium salt

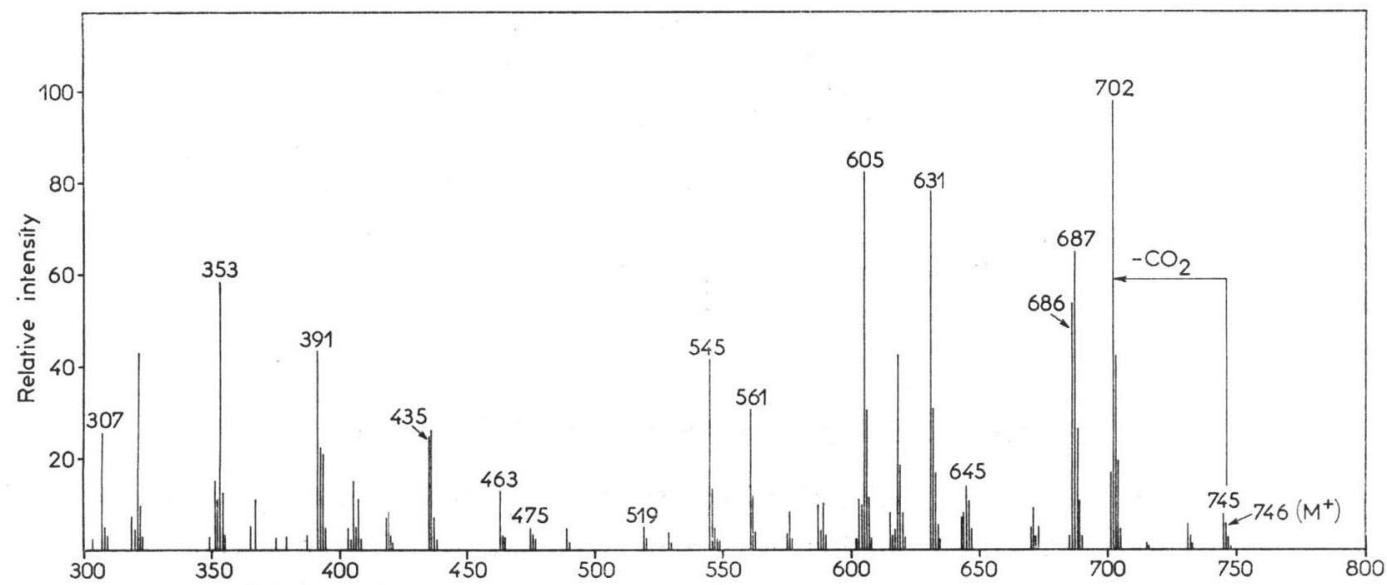

Fig. 5. Structure of the molecular ion $a$ or $b$

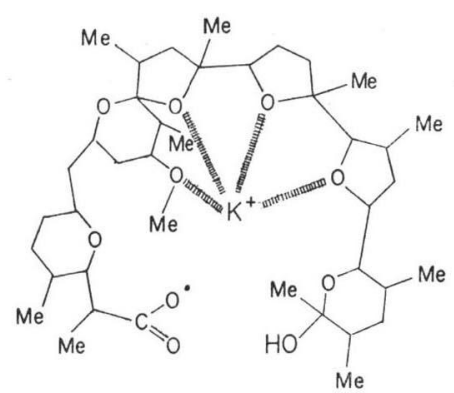

a

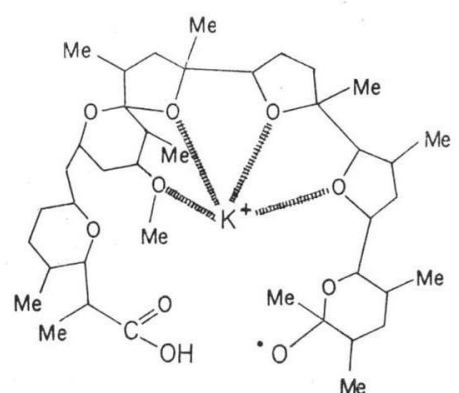

b
Fig. 6. Mass spectral fragmentation of grisorixin potassium salt.

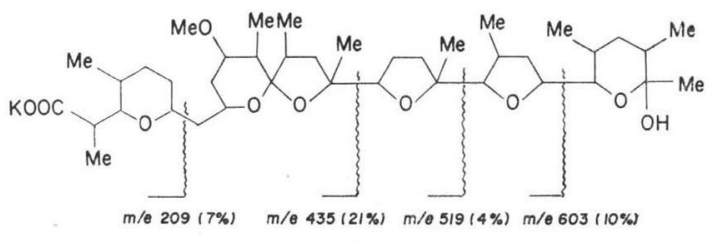

the spectra of the salts are due to fragment ions which contain the alkali metal cation. To account for the formation of such ions, one might first suppose that a molecule of the salt in the gas phase may be represented in the same way as the silver salt (Fig. 2). In the spectrum of the $\mathrm{K}^{+}$salt of grisorixin

(Fig. 4), the molecular ion peak ( $a$ or $b$ ) (Fig. 5) can be seen at $m / e 746$, as well as a very intense M-1 peak at $m / e$ 745. The base peak occurs at $m / e$ 702, and corresponds to the loss of $\mathrm{CO}_{2}$ by the parent ion. This loss of $\mathrm{CO}_{2}$ is never seen in the spectra of the uncomplexed antibiotic or its derivatives other than salts. Similar observations have been made by Chamberlin and Agtarap $\left.{ }^{\beta}\right)$ for monensin and nigericin. The fragmentation processes described by these authors can be applied to the spectra of the $\mathrm{Na}^{+}$and $\mathrm{K}^{+}$salts of grisorixin, and the cleavage patterns can be explained by analogy to the earlier work.

However, low-intensity peaks appear at $m / e$ 209, $m / e$ 435, $m / e$ 519, and $m / e 603$ which may be due to cleavage processes similar to those observed in the uncomplexed acid molecule (Fig. 6). 
Fig. 7. Mass spectral fragmentation of grisorixin methyl ester.

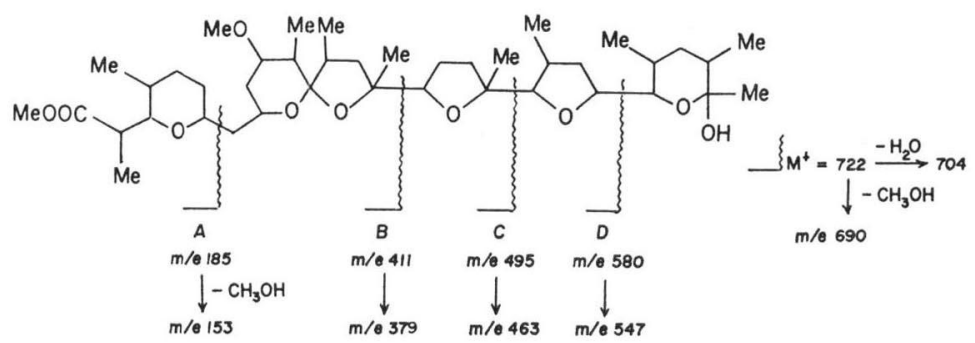

\section{Chemical Study of the Structure of Grisorixin}

We have already described the derivatives prepared by reduction, acetylation, and acid treatment of grisorixin ${ }^{7}$. The oxidation by $\mathrm{CrO}_{3}$ of grisorixin methyl ester (Fig. 7) in aqueous acetic acid was carried out at room temperature according to the method described by KuBOTA et al. ${ }^{8)}$ We have thus obtained several products, which were separated into an acidic fraction and a neutral fraction.

Fig. 7 shows the main fragment ions observed in the mass spectrum of the methyl ester of grisorixin, and which are present in the spectra of the products of chromic acid oxidation.

\section{Study of the Acidic Fraction}

This fraction was treated with diazomethane in ether. Its numerous constituents were separated by column chromatography on silica gel and purified on preparative tlc plates. Five of them have been identified, all methyl diesters.

The first one, with molecular formula $\mathrm{C}_{13} \mathrm{H}_{22} \mathrm{O}_{5}$, is the same as one of the derivatives obtained by К КвотА et al $^{\left.{ }^{8}\right)}$ during the chromic acid oxidation of nigericin methyl ester under the same conditions. The mass spectrum of this diester (Fig. 8, compound 1) shows three intense peaks at $m / e 258$ (molecular ion), $m / e 185$ (corresponds to ion $\mathrm{A}$ in the spectrum of grisorixin methyl ester), and $m / e 171$ (cleavage of the bond between the tertiary carbon and the THP ring). The signals of the ester methyl groups appear at 3.59 (s) and $3.62 \mathrm{ppm}(\mathrm{s})$ in the NMR spectrum $\left(60 \mathrm{MHz}, \mathrm{CCl}_{4}\right)$.

The second diester (Fig. 8, compound 2), with molecular formula $\mathrm{C}_{15} \mathrm{H}_{28} \mathrm{O}_{8}$, was also isolated by Kubota et al. ${ }^{8)}$ Its IR spectrum $\left(\mathrm{CCl}_{4}\right)$ shows an $\mathrm{OH}$ absorption band at $3480 \mathrm{~cm}^{-1}$ and an intense peak at $1730 \mathrm{~cm}^{-1}$ due to the ester carbonyls. The ester methyl group peaks in the NMR spectrum $\left(60 \mathrm{MHz}, \mathrm{CCl}_{4}\right)$ appear at 3.60 (s) and $3.68 \mathrm{ppm}$ (s). Lastly, the mass spectrum shows peaks at $m / e 302$ (molecular ion), $m / e 284\left(\mathrm{M}^{+}-\mathrm{H}_{2} \mathrm{O}\right), m / e 185$ (ion $\left.\mathrm{A}\right), m / e$ 215 and $m / e 117$.

The third diester, with molecular formula $\mathrm{C}_{25} \mathrm{H}_{42} \mathrm{O}_{8}$, is assigned structure 3 (Fig. 8). Its NMR spectrum $\left(60 \mathrm{MHz}, \mathrm{CCl}_{4}\right)$ shows two singlets at 3.68 and $3.71 \mathrm{ppm}$, due to the ester methyl groups, and one peak at $3.32 \mathrm{ppm}$ which reveals a methoxyl group on one of the spiroketal rings. The molecular ion peak appears at $m / e \quad 470$ in the mass spectrum. Ion A $(m / e) 185 \rightarrow 153)$ may be seen, as well as ion B $(m / e 411 \rightarrow 379)$, and a peak at $m / e 285$.

The NMR spectrum $\left(60 \mathrm{MHz}, \mathrm{CCl}_{4}\right)$ of derivative 4 (Fig. 8), with molecular formula $\mathrm{C}_{34} \mathrm{H}_{56} \mathrm{O}_{10}$, shows that it is also a methyl diester (singlets at 3.60 and $3.67 \mathrm{ppm}$ ), containing a 
spiroketal group bearing a methoxyl fonction singlet at $3.32 \mathrm{ppm})$. The structure of this derivative is further corroborated by mass spectral peaks at $m / e 624$ (molecular ion), $m / e$ $593\left(\mathrm{M}^{+}-\mathrm{CH}_{3} \mathrm{O}^{*}\right), m / e 592\left(\mathrm{M}^{+}-\mathrm{CH}_{3} \mathrm{OH}\right), m / e$ $561\left(\mathrm{M}^{+}-\mathrm{CH}_{3} \mathrm{O}^{\prime}\right.$ and $\mathrm{CH}_{3} \mathrm{OH}$ ), m/e 495 (ion $\mathrm{C}$ ), $m / e 411$ (ion B), and $m / e 185$ (ion A).

Lastly, the fifth diester isolated from the esterified acidic fraction is assigned structure 5 (Fig. 8). Only the last ring was oxidized. Its molecular formula is $\mathrm{C}_{41} \mathrm{H}_{88} \mathrm{O}_{11}$, and its mass spectrum shows ions $\mathrm{A}(m / e$ 185), B ( $m / e$ 411), and $\mathrm{C}$ ( $m / e$ 495), and a peak at $m / e 579$ corresponding to ion $\mathrm{D}$ without transfer of a hydrogen, contrary to the grisorixin methyl ester spectrum.* The ester methyl group peaks in the NMR spectrum $\left(60 \mathrm{MHz}, \mathrm{CCl}_{4}\right)$ appear at 3.62 (s) and 3.68 ppm (s).

\section{Study of the Neutral Fraction}

The constituents of this fraction were separated by column chromatography on silica gel and purified on preparative tlc plates. Many derivatives were obtained, from which only two have thus far been identified.

The first is methyl ester 6 (Fig. 8), with molecular formula $\mathrm{C}_{28} \mathrm{H}_{48} \mathrm{O}_{8}$. Its NMR spectrum $\left(60 \mathrm{MHz}, \mathrm{CCl}_{4}\right)$ shows a singlet at $3.33 \mathrm{ppm}$ due to the methoxyl group, a singlet at 3.72 ppm due to a methyl ester, and a 3-proton peak at $2.14 \mathrm{ppm}$ (s) due to a $\mathrm{CH}_{3}-\mathrm{CO}$-group. The IR spectrum (KBr) shows three carbonyl peaks at 1750,1740 , and $1725 \mathrm{~cm}^{-1}$. The main peaks of the mass spectrum correspond to ions $\mathrm{A}, \mathrm{B}$, and $\left(\mathrm{M}^{+}-\mathrm{CH}_{3} \mathrm{OH}\right)$.

The lactone 7 (Fig. 8), with molecular formula $\mathrm{C}_{40} \mathrm{H}_{66} \mathrm{O}_{10}$, is similar to that prepared by Kuвота et $a l .{ }^{8)}$ by potassium metaperiodate oxidation of nigericin methyl ester. The mass spectrum shows ions A (m/e 185), B (m/e 411), C (m/e 495), and D (m/e 579). The lactone carbonyl band appears at $1738 \mathrm{~cm}^{-1}$ in the IR spectrum $(\mathrm{KBr})$.

\section{Experimental}

\section{General}

Melting points (mp) were determined with a Reichert microscope and are uncorrected. Nmr spectra were determined with a Varian Associates HA-100 spectrometer and mass spectra

\footnotetext{
* Note that the proton transfer was not observed in the mass spectrum of nigericin methyl ester, in which ion $\mathrm{D}$ appears at $m / e 579$.
} 
were taken with a Varian MAT CH 5 spectrometer at $70 \mathrm{eV}$. Column chromatography was performed on Merck silica gel $(0.063 \sim 0.200 \mathrm{~mm})$. Analytical tlc plates were Merck (silica gel $60)$ and preparative tlc plates were prepared with Merck silica gel $\left(\mathrm{PF}_{254+388}\right)$.

Preparation of the metallic salts of grisorixin

Sodium salt: To a solution of $300 \mathrm{mg}$ of grisorixin in $20 \mathrm{ml}$ of ethanol-water (1: 1) was added $0.1 \mathrm{~N} \mathrm{NaOH}$ to $\mathrm{pH} 8.5$ ( $\mathrm{pH}$ meter). This mixture was evaporated under vacuum to dryness. The white residue obtained was dissolved in $10 \mathrm{ml}$ of methanol, and water added until slightly turbid. After several hours at room temperature, white crystals of the sodium salt precipitated. After filtration, the sodium salt was recrystallized from methanol-water as above. Recrystallized sodium salt $(280 \mathrm{mg})$ of grisorixin was obtained $\mathrm{mp}: 242 \sim 246^{\circ} \mathrm{C}$.

Calcd, for $\mathrm{C}_{40} \mathrm{H}_{87} \mathrm{O}_{10} \mathrm{Na}$ : C 65.73, H 9.24, Na 3.15.

Found: $\quad$ C $65.76, \mathrm{H} 9.49$, Na 3.18 .

Potassium salt: This salt was obtained in the same manner as above and was recrystallized twice. Thus, $500 \mathrm{mg}$ grisorixin afforded $450 \mathrm{mg}$ of recrystallized potassium salt, $\mathrm{mp}: 168 \sim 172^{\circ} \mathrm{C}$.

Calcd. for $\mathrm{C}_{40} \mathrm{H}_{67} \mathrm{O}_{10} \mathrm{~K}$ : C 64.31, H 9.04, K 5.23.

Found:

C $64.21, \mathrm{H} 9.12, \mathrm{~K} 5.06$.

Silver salt: To a solution of $330 \mathrm{mg}$ of the sodium salt in $20 \mathrm{ml}$ of aqueous ethanol $(1: 1)$ was added a solution of $80 \mathrm{mg} \mathrm{AgNO}_{3}$ in $1 \mathrm{ml}$ of water. After evaporation at room temperature in darkness, crystals of the Ag salt precipitated. These crystals were filtered and recrystallized twice from acetone-water $(1: 1)$ after standing several hours at room temperature in darkness for the $\mathrm{Ag}^{+}$salt is light-sensitive. Recrystallized $\mathrm{Ag}$ salt $(300 \mathrm{mg}$ ) was obtained, $\mathrm{mp}: \quad 147 \sim 153^{\circ} \mathrm{C}$.

Calcd. for $\mathrm{C}_{40} \mathrm{H}_{67} \mathrm{O}_{10} \mathrm{Ag}$ :

Found:

C $58.89, \mathrm{H} 8.28, \mathrm{Ag} 13.22$.

C $59.08, \mathrm{H} 8.25$, Ag 12.83 .

Thallium salt: To a solution of $300 \mathrm{mg}$ of $\mathrm{Ag}$ salt in $20 \mathrm{ml}$ of methanol-water (1: 1) was added $100 \mathrm{mg}$ of thallium chloride dissolved in a minimal amount of water. After 10 minutes, the precipitate of $\mathrm{AgCl}$ was filtered and the mixture left at room temperature for several hours. Crystals of the $\mathrm{Tl}$ salt precipitated and were recrystallized from acetone-water (1: 1) by evaporation at room temperature. Thallium $(300 \mathrm{mg})$ salt was obtained.

Calcd. for $\mathrm{C}_{40} \mathrm{H}_{87} \mathrm{O}_{10} \mathrm{Tl}$ : C 52.66, H 7.40.

Found: $\quad$ C $52.86, \mathrm{H} 7.58$.

Chromic oxidation of grisorixin methyl ester

To a solution of $4.25 \mathrm{~g}$ of grisorixin methyl ester in $55 \mathrm{ml}$ of glacial acetic acid was added slowly, with cooling and stirring, a solution of $5 \mathrm{~g} \mathrm{CrO}_{3}$ in $60 \mathrm{ml}$ of acetic acid-water $(3: 1)$. This reaction mixture was left 16 hours at room temperature, diluted with $1,000 \mathrm{ml}$ ice-water, and extracted with chloroform. The chloroform extracts were dried with $\mathrm{Na}_{2} \mathrm{SO}_{4}$ and evaporated under vacuum. The residue was dissolved in ether, extracted with aqueous $\mathrm{NaOH}(10 \%)$ and washed with water. The organic phase was dried $\left(\mathrm{Na}_{2} \mathrm{SO}_{4}\right)$ and evaporated under vacuum; $2.5 \mathrm{~g}$ of neutral oxidation products were obtained. The basic solution was acidified with $1 \mathrm{~N}$ $\mathrm{HCl}$ and extracted with ether. This organic phase was washed twice with water and dried $\left(\mathrm{Na}_{2} \mathrm{SO}_{4}\right)$. After evaporation under vacuum, $1.6 \mathrm{~g}$ of acidic oxidation products were isolated and treated with diazomethane in ether.

Acidic fraction: The numerous constituents of this fraction were first roughly separated on a silica gel column using an ether-petroleum ether mixture $(30: 70)$ as eluant. The pure products were then obtained by rechromatographing the fractions three times on preparative tlc plates with the above developing solvent.

Fifteen $\mathrm{mg}$ of the dimethyl ester 1 were obtained as an oil of Rf 0.60 .

Calcd. for $\mathrm{C}_{13} \mathrm{H}_{22} \mathrm{O}_{5}$ : C $60.45, \mathrm{H} 8.58, \mathrm{O} 30.97$.

Found: $\quad$ C $61.00, \mathrm{H} 8.70, \mathrm{O} 30.38$.

Thirty five $\mathrm{mg}$ of 2 were obtained as an oil of $\mathrm{Rf} 0.35$. 
$\begin{array}{ll}\text { Calcd. for } \mathrm{C}_{15} \mathrm{H}_{26} \mathrm{O}_{6}: & \text { C } 59.58, \mathrm{H} 8.67 \text {, O } 31.75 . \\ \text { Found: } & \text { C } 59.18, \mathrm{H} 8.28, \text { O } 32.02 .\end{array}$

Thirty five $\mathrm{mg}$ of 3 were isolated as an amorphous form of $\mathrm{Rf} 0.55$.

Calcd. for $\mathrm{C}_{25} \mathrm{H}_{42} \mathrm{O}_{8}$ : C 63.81, $\mathrm{H}$ 8.99, O 27.20.

Found: $\quad$ C 63.85, H 9.15, O 26.97.

Twenty mg of 4 were obtained as a white solid form of Rf 0.75 .

Calcd. for $\mathrm{C}_{34} \mathrm{H}_{56} \mathrm{O}_{10}$ : C 65.36, $\mathrm{H}$ 9.03, O 25.61.

Found: $\quad$ C 64.88, H 9.21, O 26.05.

Forty five $\mathrm{mg}$ of $\mathbf{5}$ were isolated as a white solid form of $\mathrm{Rf} 0.18$.

Calcd. for $\mathrm{C}_{41} \mathrm{H}_{68} \mathrm{O}_{11}$ : C 66.82, $\mathrm{H}$ 9.30, O 23.88.

Found: $\quad$ C 66.26, H 9.05, O 24.06.

Neutral fraction: The neutral oxidation products were first chromatographed on a silica gel column using an ether-petroleum ether mixture $(65: 35)$ and purified twice by preparative silica gel tlc using the same solvent.

Eighty $\mathrm{mg}$ of the methyl ester 6 were obtained as an amorphous solid form, $\mathrm{Rf} 0.55$.

Calcd, for $\mathrm{C}_{23} \mathrm{H}_{43} \mathrm{O}_{8}$ : C 65.86, $\mathrm{H} 9.08$, O 25.06.

Found: $\quad$ C 65.35, H 9.22, O 25.41.

Forty $\mathrm{mg}$ of the lactone 7 were obtained as amorphous form, $\mathrm{Rf} 0.65$.

Calcd. for $\mathrm{C}_{40} \mathrm{H}_{80} \mathrm{O}_{10}$ : C 67.96, $\mathrm{H} 9.41$.

Found: $\quad$ C $67.30, \mathrm{H} 9.32$.

Acknowledgement

We are grateful to Dr. M. Alleaume, Université de Bordeaux, France, for performing the X-ray crystallographic analysis. P. G. thanks l'Institut National de la Santé et de la Recherche Médicale for support of this work.

\section{References}

1) Gachon, P.; A. Kergomard, T. Staron \& C. Esteve: Grisorixin, an ionophorous antibiotic of the nigericin group. I. Fermentation, isolation, biological properties and structure. J. Antibiotics 28: $345 \sim 350,1975$

2) Alleaume, M. \& D. Hickel: The crystal structure of grisorixin silver salt. Chem. Comm. 1970: $1422 \sim 1423,1970$

3) Alleaume, M. \& D. Hickel: The crystal structure of thallium grisorixin monohydrate. Chem. Comm. 1972: 175 176, 1972

4) Lutz, W. K.; H. K. Wipf \& W. Simon: Alkalikationen-spezifität und Träger-eigenschaften der Antibiotica Nigericin und Monensin. Helv. Chim. Acta 53: 1741 1746, 1970

5) Gachon, P.; G. Chaput, G. Jeminet, J. Juillard \& J. P. Morel: Grisorixin, an ionophorous antibiotic of the nigericin group. IV. Complexation of monovalent cations. J. C. S. Perkin II: in press

6) Chamberlin, J.W. \& A. Agtarap: Observations on the mass spectrometry of monensin and related compounds. Org. Mass Spectrum. 3: 271 285, 1970

7) Gachon, P.; A. Kergomard, H. Veschambre, C. Esteve \& T. Staron: Grisorixin, a new antibiotic related to nigericin. Chem. Comm. 1970: 1421 1422, 1970

8) Kubota, T. \& S. Matsutani: Studies on the antibiotic nigericin (polyetherin A). J. Chem. Soc. (C) 1970: 685 703, 1970 